\title{
Extrahepatic Bile Duct Mucinous Cystic Neoplasm
}

National Cancer Institute

\section{Source}

National Cancer Institute. Extrahepatic Bile Duct Mucinous Cystic Neoplasm. NCI

Thesaurus. Code C5851.

A mucinous cystic neoplasm that arises from the extrahepatic bile ducts. 